\title{
A Modern Approach to the Molecular Diagnosis of Inherited Bleeding Disorders
}

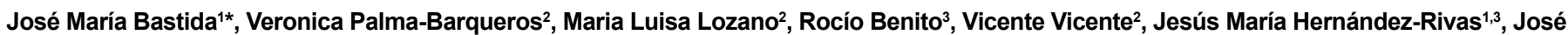
Rivera $^{2}$ and José Ramón González-Porras ${ }^{1}$

${ }^{1}$ Servicio de Hematología, Hospital Universitario de Salamanca-IBSAL-USAL, Salamanca

${ }^{2}$ Servicio de Hematología y Oncología Médica, Hospital Universitario Morales Meseguer, Centro Regional de Hemodonación, Universidad de Murcia, IMIB-Arrixaca, CB15/00055CIBERER, Murcia

${ }^{3}$ IBSAL, IBMCC, CIC, Universidad de Salamanca-CSIC, Salamanca, Spain

\begin{abstract}
Diagnosis of inherited bleeding disorders (IBDs) requires careful evaluation of patients' clinical features and assessment of bleeding with the appropriate tools. Definitive diagnosis can be achieved by platelet functional assays for some disorders, but, in most cases, these tests are not sufficiently sensitive or specific. Moreover, tests are hindered by the need for relatively large samples of fresh blood. Identifying the underlying molecular defect not only facilitates a definitive diagnosis of an IBD, but may also help with the clinical prognosis, and enable genetic counseling. Until recently, molecular diagnosis has relied on Sanger sequencing of single or small numbers of candidate genes that are already known to cause some inherited platelet disorders. High-throughput sequencing (HTS) technologies have revolutionized molecular diagnosis of human disease, since they allow simultaneous, rapid and affordable investigation of multiple genes. HTS is being widely implemented and is rapidly improving the molecular characterization of IBDs in routine clinical practice.
\end{abstract}

Keywords: Inherited platelet disorders; Inherited rare bleeding disorders; Hemophilia A and B; High-throughput sequencing

\section{Introduction}

Inherited bleeding disorders (IBDs) are a heterogeneous group of hemorrhagic diseases caused by variants in genes involved in megakaryopoiesis and platelet function, or in those related to coagulation factor deficiencies, such as inherited platelet disorders (IPDs), von Willebrand disease (VWD), hemophilia $\mathrm{A}(\mathrm{HA})$ and $\mathrm{B}(\mathrm{HB})$, and rare bleeding disorders (RBDs) [1,2]. Genetic diagnosis is not only essential for the accurate diagnosis of IBDs, which facilitates better clinical care, prognosis and preventive treatments, but also for identifying patients with a high risk of malignancy, and for determining carrier status. This information facilitates genetic counseling, clarifies differential diagnosis between similar phenotypes, and predicts the likelihood of inhibitor development in cases of HA [3,4]. Successful genotyping has customarily relied on Sanger sequencing (SS) of candidate genes, guided by phenotyping $[4,5]$. However, this approach is currently costly and time-consuming, and is not applicable to disorders whose phenotypebased diagnosis is not straightforward and for which there is no obvious candidate gene to analyze [5-7]. In particular, diagnosis of inherited platelet disorders (IPDs) is usually hampered by a lack of distinctive clinical and laboratory features, and genetic diagnosis remains a challenge even with expert analysis, such that it has been attained in fewer than half of patients [5-8]. On the other hand, molecular testing based on SS of candidate genes in clear phenotypes, such as in some IPDs (e.g., Hermansky-Pudlak syndrome [HPS], Glanzmann Thrombastenia [GT]) and RBDs, is also hindered by the wide range of exons, the large size and complex genomic organization of the genes involved, and by the heterogeneity of the pathogenic variants underlying these disorders [5-10]. Customarily, molecular diagnosis of HA starts by screening for the presence of intron 22 and intron 1 inversions (IVS-22 and IVS-1) in severe patients (by inverse PCR and PCR amplification), followed by SS in negative IVS-22 or IVS-1 severe HA patients. Similarly, the remaining $\mathrm{HA}$ and all $\mathrm{HB}$ patients are usually analyzed by single-gene sequencing $[2,4]$, which is laborious due to the length and wide range of exons of $F 8[2,4]$. Moreover, deep intronic variants have been involved in cases of mild-to-moderate HA phenotypes [11], and low factor VIII levels in HA patients without identified $F 8$ variants may be caused by $V W F$ variants [12].

\section{Literature Review}

The recent advent of high-throughput sequencing (HTS) - wholegenome sequencing (WGS) and whole-exome sequencing (WES)and targeted sequencing of pre-specified genes, has revolutionized the field of genetic diagnosis and is rapidly becoming recognized as a unique tool in clinical practice $[4,5,7,9,10]$. WGS determines the complete genomic information, including all the coding and noncoding sequences, although the method is relatively fast and requires samples that are simple to prepare; the large amount of data needs an extensive and complex filtered workflow to establish the diseasecausing variants [13]. WES and a panel of pre-specified genes target all exons from all genes (WES) or only regions from genes of predefined interest (panel). These approaches require library preparation protocols, design, and enrichment assays to achieve accurate variant calling that enables the relevant causative variants to be defined [10,13]. Panels offer better base-pair coverage, running times, costs and dataset handling than other HTS applications, such as WGS and WES. In any case, HTS is emerging as a valuable tool in molecular diagnosis and is increasingly important in the first-line of diagnostic investigation of these diseases $[4,5,7,9,10,13]$. In the context of IBDs, the initial steps in targeted DNA sequencing were undertaken by the ThromboGenomics (TG) and UK Genotyping and Phenotyping of Platelets (UK-GAPP) consortia [5,9,14-16]. TG reported on a targeted HTS panel platform, originally comprising 63 genes (Tier 1) for the diagnosis of inherited thrombotic conditions and IBDs, while the UK-GAPP study used WES to investigate IPDs, especially inherited thrombocytopenias $[5,9]$.

*Corresponding author: Dr. José María Bastida, Unidad de Hemostasia y Trombosis, Servicio de Hematología, Hospital Universitario de Salamanca-IBSAL, Paseo de San Vicente 58-182, 37007 Salamanca, Spain, Tel: +34 923090470; E-mail: jmbastida@saludcastillayleon.es

Received January 27, 2018; Accepted January 30 2018; Published February 02, 2018

Citation: Bastida JM, González-Porras JR, Palma-Barqueros V, Lozano ML, Vicente V, et al. (2018) A Modern Approach to the Molecular Diagnosis of Inherited Bleeding Disorders. J Mol Genet Med 12: 322 doi:10.4172/1747-0862.1000322

Copyright: @ 2018 Bastida JM, et al. This is an open-access article distributed under the terms of the Creative Commons Attribution License, which permits unrestricted use, distribution, and reproduction in any medium, provided the original author and source are credited 
Recently, TG incorporated 23 new genes discovered by WES or WGS, such as SRC, DIAPH1, TPM4, ABCC4 and KDSR; in total, 3449 DNA samples were analyzed by a 79-gene TG platform and demonstrated the success of HTS approaches in providing a genetic diagnosis for patients with well-defined inherited platelet or coagulation defects [17]. Other groups have incorporated HTS technology into the molecular diagnosis of HA, sequencing the entire F8 gene, and detecting deep intronic variants that may be the causative variant of mild HA and combined F8/VWF genes $[11,12]$; the Scandinavian group has used the WES approach to identify genes related to IPD and Ehlers-Danlos syndrome [18]. In Spain and Portugal, HTS has been successfully used for the genetic analysis of IBDs $[4,7,10]$.

In the context of IPDs, we have recently reported the design and implementation of a multigenic HTS platform, based on a panel of 72 IPD-related genes, which has greatly aided our diagnostic process, resulting in a conclusive molecular diagnosis (70\%) in the largest series of IPD patients investigated so far in the Iberian Peninsula [19]. We found 57 candidate variants in 28 genes, $70 \%$ of which had not previously been described. This approach allowed us to identify a novel microdeletion in exon 9 of the WAS gene in Wiskott-Aldrich syndrome in a child presenting with macrothrombocytopenia [20], two novel variants of the ABCG5 gene that caused sitosterolemia in a 46-yearold female with life-long macrothrombocytopenia and xanthelasmas [21], and four novel variants in the RASGRP2 gene that affected platelet CalDAG-GEFI expression and function in patients with severe bleeding diathesis $[22,23]$. It is important to note that finding a novel gene variant is not by itself definitive proof that it is the cause of the disease. Analysis of the association of the variant with the disease in the family, structure/function studies of the protein, and studies of mouse or zebrafish models are often necessary [19]. We designed and applied a 23-gene panel related to RBDs to identify the disease-causing variant in 20 patients with bleeding and coagulation factor deficiencies. Twentyone pathogenic variants were found, most of which were of the missense type (18), and six were novel variants affecting the $F 8, F G A, F 11, F 10$ and $V W F$ genes [10]. We have also incorporated and evaluated the usefulness of a molecular algorithm employing an HTS approach for sequencing the complete $F 8, F 9$ and $V W F$ genes for patients with factor VIII or IX deficiencies. This algorithm contemplates the detection of IVS-1 and IVS-22 by classical methods, the sequencing of the entire $F 8, F 9$ and VWF genes by HTS, and multiplex ligation-dependent probe amplification analysis. The proposed algorithm had an overall success rate of $99 \%$ [4]. Finally, the complete coding of VWF by HTS technology was carried out in two multicenter studies, including 556 Spanish and 92 Portuguese patients [24,25].

\section{Discussion}

Although these reports reinforce the feasibility of introducing HTS into the mainstream laboratory for the genetic diagnosis of IBDs (Figure 1), there are several limitations $[4,9,10,13,14,18]$ : a) the great heterogeneity of the molecular pathology underlying IPDs hampers the appropriate interpretation of the pathogenicity of candidate genetic variants and remains a major challenge, especially for novel variants and those of uncertain significance; b) HTS cannot completely replace clinical evaluation and laboratory phenotyping, because it may not be able to identify the causative variant in patients with a strongly specific phenotype; c) rearrangements, inversions and large deletions/insertions, mainly in HA, cannot be identified in many cases; $d$ ) the need to examine experimental, in vitro or animal models to determine the pathogenicity of the novel variants; and e) there is a clear need for a consensus guidance to report HTS results, including incidental findings [26].

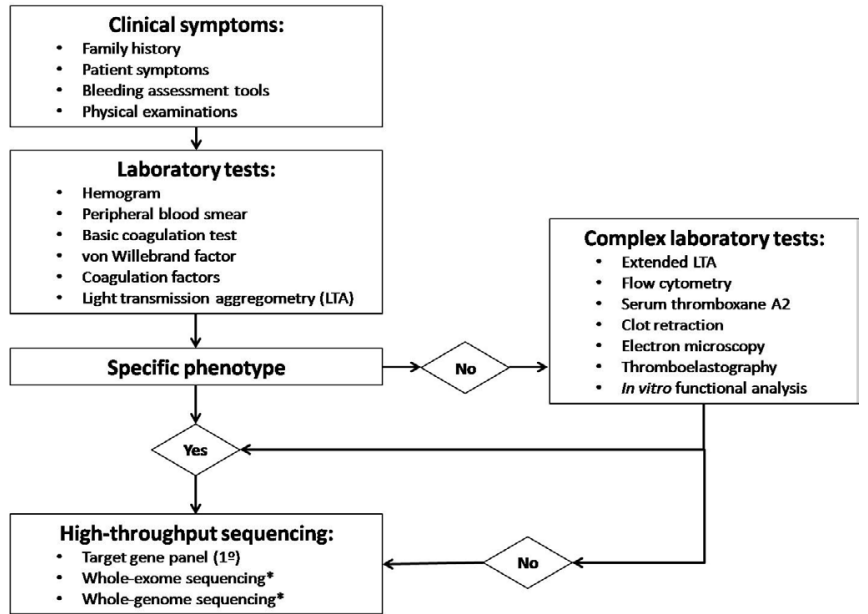

Note: The diagnostic process consists of obtaining: an accurate family history of bleeding, thrombocytopenia or malignancies; information about clinical symptoms related to bleeding, systemic disease and thrombocytopenia, and from physical examinations. Bleeding assessment tools (ISTH-BATs) are recommended. Laboratory investigation includes hemogram, peripheral blood smear and basic coagulation tests, and von Willebrand antigen and activity and other coagulation factor tests. We recommend introducing an HTS gene panel at any moment in the diagnostic flowchart for patients with specific or nonspecific phenotypes in laboratory testing. *WES or WGS are most strongly indicated in patients with an unambiguous clinical suspicion of IBD but with a nonspecific laboratory phenotype, and for whom the HTS gene panel fails to identify candidate variants.

Figure 1: Incorporation of genetic analysis by HTS into the diagnostic process for inherited bleeding disorders.

\section{Conclusion}

In conclusion, the simultaneous analysis of several genes by HTS, target gene panel or WES, is a powerful tool with which to meet the increasing demand for medical accuracy in the era of precision medicine. These cost-effective technological advancements are revolutionizing the ability of medical professionals to diagnose IBDs and to improve the provision of care to patients with these disorders.

\section{Conflict of Interest Disclosure}

The authors declare no competing financial interests. This study was supported by research grants from the Gerencia Regional de Salud (GRS 1647/A/17 and GRS 1650/A/17), ISCIII \& Feder (PI17/01966), CIBERER CB15/00055, Fundación Séneca (19873/GERM/15) and Sociedad Española de Trombosis y Hemostasia (SETH).

\section{Acknowledgements}

We are grateful to all the patients and their families for providing samples and to the clinicians and technicians involved in these projects. We thank Dr. Phil Mason for his help with technical aspects.

\section{Author Contributions}

All authors contributed to the conception and design of the study, the acquisition, analysis or interpretation of the data, drafting the manuscript or critically revising it for important intellectual content. All authors approved the final version for publication.

\section{References}

1. Nurden AT, Nurden $P$ (2015) Inherited disorders of platelet function: Selected updates. J Thromb Haemost 13: S2-S9.

2. Blanchette VS, Key NS, Ljung LR, Manco-Johnson MJ, Van den Berg HM, et al. (2014) Definitions in hemophilia: Communication from the SSC of the ISTH. J Thromb Haemost 12: 1935-1939.

3. Gresele P, Bury L, Falcinelli E (2016) Inherited platelet function disorders Algorithms for phenotypic and genetic investigation. Semin Thromb Hemost 42: $292-305$ 
Citation: Bastida JM, González-Porras JR, Palma-Barqueros V, Lozano ML, Vicente V, et al. (2018) A Modern Approach to the Molecular Diagnosis of Inherited Bleeding Disorders. J Mol Genet Med 12: 322 doi:10.4172/1747-0862.1000322

Page 3 of 3

4. Bastida JM, González-Porras JR, Jiménez C, Benito R, Ordoñez GR, et al. (2017) Application of a molecular diagnostic algorithm for haemophilia $A$ and $B$ using next-generation sequencing of entire F8, F9 and VWF genes. Thromb Haemost 117: 66-74

5. Lentaigne C, Freson K, Laffan MA, Turro E, Ouwehand WH (2016) Inherited platelet disorders: Toward DNA-based diagnosis. Blood 127: 2814-2823.

6. Sánchez-Guiu I, Antón AI, Padilla J, Velasco F, Lucia JF, et al. (2014) Functional and molecular characterization of inherited platelet disorders in the Iberian Peninsula: Results from a collaborative study. Orphanet J Rare Dis 9: 213.

7. Bermejo JMB, Hernández-Rivas JM, González-Porras JR (2017) Nove approaches for diagnosing inherited platelet disorders. Med Clin 148: 71-77.

8. Watson SP, Lowe GC, Lordkipanidzé M, Morgan NV (2013) Genotyping and phenotyping of platelet function disorders. J Thromb Haemost 11: 351-363.

9. Simeoni I, Stephens JC, Hu F, Deevi SV, Megy K, et al. (2016) A highthroughput sequencing test for diagnosing inherited bleeding, thrombotic, and platelet disorders. Blood 127: 2791-2803.

10. Bastida JM, del Rey M, Lozano ML, Sarasquete ME, Benito R, et al. (2016) Design and application of a 23-gene panel by next-generation sequencing for inherited coagulation bleeding disorders. Haemophilia 22: 590-597.

11. Bach JE, Wolf B, Oldenburg J, Müller CR, Rost S (2015) Identification of deep intronic variants in 15 haemophilia $A$ patients by next generation sequencing of the whole factor VIII gene. Thromb Haemost 114: 757-767.

12. Boylan B, Rice AS, De Staercke C, Eyster ME, Yaish HM, et al. (2015) Hemophilia Inhibitor Research Study Investigators. Evaluation of von Willebrand factor phenotypes and genotypes in Hemophilia A patients with and without identified F8 mutations. J Thromb Haemost 13: 1036-1042.

13. de Koning TJ, Jongbloed JD, Sikkema-Raddatz B, Sinke RJ (2015) Targeted next-generation sequencing panels for monogenetic disorders in clinical diagnostics: The opportunities and challenges. Expert Rev Mol Diagn 15: 61-70.

14. Freson K, Turro E (2017) High-throughput sequencing approaches for diagnosing hereditary bleeding and platelet disorders. J Thromb Haemost 15 : 1262-1272.

15. Leo VC, Morgan NV, Bem D, Jones ML, Lowe GC, et al. (2015) Use of nextgeneration sequencing and candidate gene analysis to identify underlying defects in patients with inherited platelet function disorders. J Thromb Haemost 13: $643-650$
16. Johnson B, Lowe GC, Futterer J, Lordkipanidzé M, MacDonald D, et al (2016) Whole exome sequencing identifies genetic variants in inherited thrombocytopenia with secondary qualitative function defects. Haematologica 101: 1170-1179.

17. Lentaigne C, Ouwehand W (2017) High throughput sequencing in 3449 patients with bleeding and platelet disorders: Novel gene discovery and robust diagnosis. Blood 130: 5.

18. Leinøe E, Zetterberg E, Kinalis S, Østrup O, Kampmann P, et al. (2017) Application of whole-exome sequencing to direct the specific functional testing and diagnosis of rare inherited bleeding disorders in patients from the Öresund Region, Scandinavia. Br J Haematol 179: 308-322.

19. Bastida JM, Lozano ML, Benito R, Janusz K, Palma-Barqueros V, et al. (2018) Introducing high-throughput sequencing into mainstream of genetic diagnosis practice in inherited platelet disorders. Haematologica 103: 148-162.

20. Bastida JM, Del Rey M, Revilla N, Benito R, Perez-Andrés M, et al. (2017) Wiskott-Aldrich syndrome in a child presenting with macrothrombocytopenia. Platelets 28: 417-420.

21. Bastida JM, Benito R, Janusz K, Díez-Campelo $M$, Hernández-Sánchez JM et al. (2017) Two novel variants of the ABCG5 gene cause xanthelasmas and macrothrombocytopenia: A brief review of hematologic abnormalities of sitosterolemia. J Thromb Haemost 15: 1859-1866.

22. Lozano ML, Cook A, Bastida JM, Paul DS, Iruin G et al. (2016) Novel mutations in RASPGRP2 encoding for CalDAG-GEFI abrogate Rap1 activation causing platelet dysfunction. Blood 128: 1282-1289.

23. Sevivas T, Bastida JM, Paul DS, Caparros E, Palma-Barqueros V, et al. (2017) Identification of two novel mutations in RASGRP2 affecting platelet CalDAG-GEF expression and function in patients with bleeding diathesis. Platelets 1: 1-4.

24. Batlle J, Pérez-Rodríguez A, Corrales I, López-Fernández MF, Rodríguez-Trillo Á, et al. (2015) Molecular and clinical profile of von Willebrand disease in Spain (PCM-EVW-ES): Proposal for a new diagnostic paradigm. Thromb Haemost 115: 40-50.

25. Fidalgo T, Salvado R, Corrales I, Pinto SC, Borràs N, et al. (2016) Genotypephenotype correlation in a cohort of Portuguese patients comprising the entire spectrum of VWD types: Impact of NGS. Thromb Haemost 116: 17-31.

26. Knoppers BM, Nguyen MT, Sénécal K, Tassé AM, Zawati MH (2016) Nextgeneration sequencing and the return of results. Cold Spring Harb Perspect Med 3: 6. 